\title{
Desenvolvimento costeiro na Amazônia: problemas socioambientais do litoral Paraense, Brasil
}

Esta pesquisa teve objetivo de identificar os problemas socioambientais nas principais praias oceânicas do litoral paraense (Pará, Amazônia, Brasil) e discuti-los com ênfase no planejamento, gerenciamento e desenvolvimento dessa região. As praias estudadas foram Ajuruteua (Bragança), Princesa (Maracanã), Atalaia e Maçarico (Salinópolis). Foram utilizados os métodos da Capacidade de Carga Recreacional (CCR) e DPSIR. Os parâmetros utilizados na avaliação da qualidade da água apresentaram-se insatisfatórios para as praias de Ajuruteua, Maçarico e Atalaia. A qualidade ecológica da praia da Princesa foi considerada excelente. A praia do Atalaia apresentou melhores índices de qualidades de serviços. A CCR apresentou diminuição na capacidade de todas as praias. A análise do DPSIR demonstrou o Estado das quatro praias. As pressões naturais e antrópicas observadas foram erosão, elevada precipitação, alta turbidez da água, a falta de planejamento para o desenvolvimento socioeconômico, uso e ocupação desordenado do solo, ausência de saneamento e ausência de gerenciamento costeiro e infraestrutura adequada. Os problemas socioambientais revelam que as praias do Atalaia e Ajuruteua são as mais impactadas. O Estado em que as praias se encontram sugerem que não houve planejamento para o desenvolvimento socioeconômico do litoral paraense e que as políticas públicas adotadas pelos municípios não estão sendo aplicadas.

Palavras-chave: Planejamento; Gerenciamento costeiro; Políticas públicas; Praia.

\section{Coastal development in the Amazon: socio-environmental problems on the coast of Pará, Brazil}

\begin{abstract}
This research aimed to identify the socioenvironmental problems in the main ocean beaches on the coast of Pará (Pará, Amazonia, Brazil) and discuss them with emphasis on the planning, management and development of this region. The analyzed beaches were Ajuruteua (Bragança), Princesa (Maracanã), Atalaia and Maçarico (Salinópolis). The recreational carrying capacity (RCC) and DPSIR methods were used. The parameters used to assess water quality were unsatisfactory for the beaches of Ajuruteua, Maçarico and Atalaia. The ecological quality of Princesa beach was considered excellent. Atalaia beach had better service quality indexes. The RCC showed a decrease in the capacity of all beaches. The DPSIR analysis showed the state of the four beaches. The natural and anthropogenic pressures observed were erosion, high rainfall, high water turbidity, lack of planning for socioeconomic development, disordered land use and occupation, lack of sanitation and lack of coastal management and adequate infrastructure. Socio-environmental problems reveal that Atalaia and Ajuruteua beaches are the most impacted. The state in which the beaches are located suggests that there was no planning for the socioeconomic development of the coast of Pará and that the public policies adopted by the municipalities are not being applied.
\end{abstract}

Keywords: Planning; Coastal management; Public policy; Beach.

Topic: Engenharia Ambiental

Reviewed anonymously in the process of blind peer.
Received: $10 / 11 / 2020$

Approved: 15/02/2021
Hyago Elias Nascimento Souza

Universidade do Estado do Pará, Brasil

http://lattes.cnpq.br/9712810427104066

http://orcid.org/0000-0001-8765-2981

eng.hyagosouza@gmail.com
Referencing this:

SOUZA, H. E. N. Desenvolvimento costeiro na Amazônia: problemas socioambientais do litoral Paraense, Brasil. Natural Resources, v.11, n.1, p.62-73, 2021. DOI: http://doi.org/10.6008/CBPC2237$\underline{9290.2021 .001 .0009}$ 


\section{INTRODUÇÃO}

Até a segunda metade do século XX, as cidades litorâneas da costa amazônica brasileira, caracterizavam-se como pequenas vilas de pescadores artesanais. Com o modelo de desenvolvimento implantado pelo governo de Juscelino Kubitscheck (1956-1961), diversos investimentos públicos nas áreas de transporte, habitação, e turismo contribuíram para promover alterações no uso e ocupação dos territórios litorâneos no Estado do Pará. Na década de 1990, o litoral paraense passou a ter um aumento substancial da atividade turística envolvendo segmentos nacionais e internacionais (ALMEIDA et al., 2020).

As cidades de Salinópolis e Bragança foram as pioneiras no turismo balnear regional do litoral paraense. As praias oceânicas presentes nesses municípios receberam investimentos para a expansão rodoviária, urbanização e o desenvolvimento do turismo. Com isso, a tranquilidade das vilas de pescadores foi substituída pela movimentação de turistas, passando a demandar cada vez mais de serviços turísticos, construções imobiliária e urbanização (ALMEIDA et al., 2018). Sousa et al. (2017) explicam que diferentes de outras regiões do Brasil, o principal período de lazer na costa amazônica coincide com as férias escolares de julho (veraneio amazônico) e feriados prolongados durante o segundo semestre do ano.

O litoral no nordeste paraense é constituído por aproximadamente 15 grandes baías associadas à rios e igarapés. Além disso, praias estuarinas e oceânicas, extensas florestas de mangue e campos de dunas compõem a paisagem deste litoral (PEREIRA et al., 2018; SOUZA et al., 2019). Essas características naturais promovem um isolamento relativo da região, dificultando o acesso as praias e ao desenvolvimento do turismo costeiro. Como resultado, apenas um número reduzido de praias da região é utilizado tradicionalmente para atividades de lazer (SOUSA et al., 2017).

As praias mais populares durante o veraneio amazônico são Atalaia, Ajuruteua e Princesa, localizadas nos municípios de Salinópolis, Bragança e Marapanim, respectivamente (ALMEIDA et al., 2020). Contudo, o uso intensivo destas praias, pressão humana sobre os recursos naturais e a falta de planejamento urbano tem desencadeado significativos problemas socioambientais. Tais problemas têm afetado a costa local, alterando as condições naturais e prejudicando atividades recreativas e econômicas (SOUSA et al., 2017; PEREIRA et al., 2018).

Os municípios costeiros do nordeste paraense são pequenos, com pouca infraestrutura urbana e população relativamente baixa. Entretanto, em época de alta temporada, o turismo em massa pode aumentar temporariamente o número de habitantes em até 6 vezes (MARTINELLI FILHO et al., 2019). Esse aumento pode sobrecarregar o sistema urbano da região, aumentando significativamente a poluição do ambiente, principalmente através de resíduos sólidos (lixo) e esgoto doméstico (JAMBECK et al., 2015).

Sousa et al. (2017) ressaltam que a poluição das praias através da emissão de esgoto doméstico é um dos principais problemas socioambientais das praias paraense. Esta situação tem impacto direto na qualidade da água das praias, principalmente durante o veraneio amazônico. Martinelli Filho et al. (2019) ainda comentam que a falta de planejamento durante períodos de alta temporada pode gerar uma expressiva quantidade de plásticos e microplásticos nas praias afetando a biodiversidade marinha e estuarina 
e as comunidades locais.

A falta de planejamento no desenvolvimento da costa amazônica tem gerado conflitos e problemáticas socioambientais na região. Santos et al. (2020) destacam que os principais problemas observados na praia do Lembe, em Marapanim (PA), são a construção irregular de barracas (bares e restaurantes) e o descarte de seus resíduos sólidos diretamente no mar ou no manguezal. Mesmo esta região estando dentro de uma Unidade de Conservação (UC) e portando grande biodiversidade biológica, étnica e cultural, ela não está isenta dessas problemáticas observadas ao longo do litoral paraense.

Nesse contexto, os problemas socioambientais surgem quando nenhuma política regulatória é implementada para garantir a qualidade da praia ou do visitante. O planejamento adequado da gestão costeira e as políticas públicas para o desenvolvimento do turismo são essenciais para evitar ou mitigar os impactos causados por processos naturais e antropogênicos. Essas políticas devem ser aplicadas pela gestão pública local juntamente ao setor privado, turistas e moradores locais (COELHO-PESSOA et al., 2019).

A elaboração de políticas públicas desatualizadas e que não atendem a necessidade real da comunidade é motivada pela ausência da participação da população local no planejamento dessas políticas. A formulação e implementação de programas e projetos a partir da atuação de atores sociais contribui significativamente para o desenvolvimento local e solução de problemas socioambientais (ALMEIDA et al., 2019).

\section{REVISÃO TEÓRICA}

\section{Gerenciamento costeiro}

Como estratégia para resolução de conflitos ambientais e socioeconômicos, o gerenciamento costeiro passou a ser aplicado de forma integrada, superando a gestão fragmentada baseada em ações desconexas. Seu principal objetivo visa a preservação e a proteção da produtividade e da biodiversidade dos ecossistemas. E, pode ser entendido, como um processo contínuo e dinâmico de formulação de políticas públicas para o uso sustentável de áreas costeiras e marinhas (GRILLI et al., 2017).

O Plano Nacional de Gerenciamento Costeiro (PNGC), Lei № 7.661/1988, define a zona costeira como um espaço geográfico de interação do ar, do mar e da terra, incluindo seus recursos renováveis ou não, abrangendo uma faixa marítima e outra terrestre. Nesse sentido, o gerenciamento costeiro permite a gestão de utilização dos recursos da zona costeira através de instrumentos específicos e políticas públicas (OLIVEIRA et al., 2017)

Os ambientes costeiros, principalmente as praias, são alvo de atividades turísticas e recreativas sendo um componente importante para as economias locais e nacionais (SOUSA et al., 2017). O uso de praias sem o gerenciamento adequado pode gerar problemas ambientais como o descarte de resíduos sólidos por turistas e comerciantes. A presença de lixo nas praias pode afetar suas características naturais, prejudicar a fauna local, reduzir o valor cultural e econômico das praias desencadeando problemas ecológicos e econômicos na região (ANDRADES et al., 2020). 
Cavalcante et al. (2020) explicam que resíduos sólidos, de qualquer fonte, descartados no ambiente costeiro e marinho são definidos como lixo marinho. Esse tipo de lixo pode ser transportado para outras regiões alcançando ambientes preservados sem nenhum contato humano. Nesse contexto, a crescente preocupação com a preservação e conservação da paisagem e com o turismo nas áreas costeiras, visa a intervenção dos governos no planejamento e desenvolvimento do turismo, ocupação do solo e conservação da biodiversidade (CRISTIANO et al., 2020).

As praias localizadas na costa amazônica brasileira são pouco povoadas ou mesmo desabitadas. Muitas delas podem ser classificadas como praias rurais, e algumas outras como praias urbanas, situadas em áreas densamente povoadas (ALMEIDA et al., 2020). As pressões e conflitos antropogênicos que podem ser observados nas praias amazônicas incluem a falta de regulamentação na ocupação do solo, presença de fossas, resíduos sólidos e descargas ilegais de esgoto em manguezais e dunas (COELHO-PESSOA et al., 2019; PEREIRA et al., 2018).

O crescente aumento do uso e ocupação das praias amazônicas eleva a frequência e intensidade desses problemas socioambientais evidenciado a necessidade urgente da implementação de planos adequados de gerenciamento costeiro para o litoral amazônico (COELHO-PESSOA et al., 2019). Contudo, ainda existe a necessidade de compreender melhor esses problemas e quais localidades eles podem estar ocorrendo em maior intensidade. Nesse sentido, este trabalho buscou identificar e discutir os problemas socioambientais nas principais praias oceânicas do litoral paraense (Pará, Amazônia, Brasil) e as políticas de gestão e desenvolvimento dessa região.

\section{METODOLOGIA}

\section{Área de estudo}

O Pará possui um litoral de aproximadamente $2700 \mathrm{~km}$, com mais de 450 praias influenciadas por águas estuarinas e oceânicas dominadas por marés (PEREIRA et al., 2018). A mesorregião do nordeste paraense, possui uma costa altamente recuada e uma extensa floresta de mangue conhecida como Costa de Manguezais de Macromaré da Amazônia (SOUZA et al., 2019). É nesta região que ficam as praias mais populares durante a alta temporada, alvos deste estudo (ALMEIDA et al., 2018).

A área de estudo abrangeu a praia de Ajuruteua e praia da Princesa, localizadas nos municípios de Bragança e Maracanã, respectivamente. E as praias do Atalaia e Maçarico, ambas localizadas no município de Salinópolis (Figura 1). As praias estudadas são cercadas por dunas, estuários, lagoas e manguezais. Todas elas são ocupadas pela população tradicional e recebem um expressivo número de turistas, principalmente durante o veraneio amazônico (PEREIRA et al., 2014). 


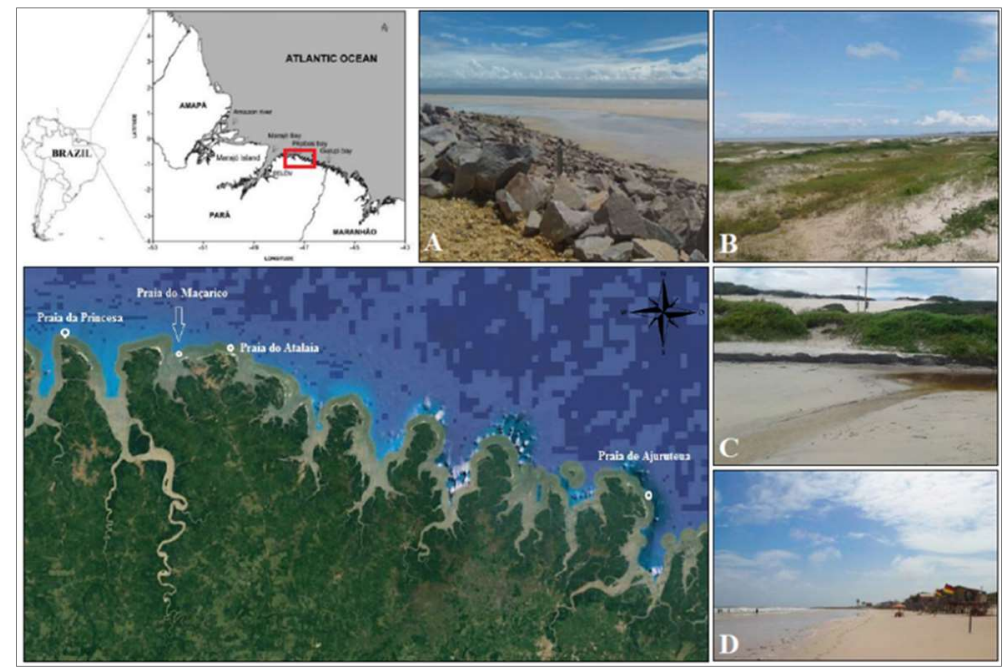

Figura 1: Localização das praias oceânicas no litoral paraense, costa amazônica. Praia de Ajuruteua (A), Praia do Maçarico (B), Praia do Atalaia (C), Praia da Princesa (D). Fonte: Adaptado de Pereira et al. (2014).

\section{Capacidade de Carga Recreacional e Estrutura do DPSIR}

Para análise das praias foram utilizados os métodos da Capacidade de Carga Recreacional (CCR) e o método do DPSIR baseado em Sousa et al. (2017), Pereira et al. (2014), Sousa-Felix et al. (2017) e Monteiro et al. (2016).

A Capacidade de Carga Recreacional é uma metodologia que busca estabelecer o número máximo de pessoas (turistas) que podem ser tolerados em uma área com base nos dados físicos, condições naturais, planejamento e gestão. Para aplicação da Capacidade de Carga Recreacional foi levado em consideração os seguintes indicadores: Área total e área utilizada, capacidade de carga física, qualidade da água, qualidade ambiental, qualidade ecológica e qualidade de serviços. Os indicadores são descritos em Sousa et al. (2017) e analisados através da equação:

\section{$C C R=C C F \times Q A \times Q A m b \times Q E \times Q S$}

Onde, $C C F=$ capacidade de carga física, $Q A$ = qualidade da água, $\mathrm{QAmb}=$ qualidade ambiental, $\mathrm{QE}=$ qualidade ecológica, QS = qualidade de serviços.

Os procedimentos metodológicos, dados e variáveis utilizados para analisar cada índice dos indicadores seguiram os procedimentos utilizados por Sousa et al. (2017). Os indicadores de qualidade (QA, QAmb, QE, QS) representam os principais fatores de influência na qualidade geral do gerenciamento das praias e são utilizadas como ajuste na capacidade de carga física que cada ambiente pode ter, refletindo as reais condições da CCR e desenvolvimento do local (PEREIRA et al., 2014).

O método de DPSIR (Driver-Pressure-State-Impact-Responses) leva em consideração a observação e análise de forçantes naturais e antrópicas, pressões, estado, impactos e respostas. É uma ferramenta que integra variáveis qualitativas e quantitativas das interações sociais e ambientais que são observadas no ambiente. É utilizada para diagnosticar as complexas interações sociais, econômicas e ambientais, fornecendo uma visão integrada do sistema e proporcionando abordagens de planejamento e gerenciamento da região (PINTO et al., 2013; SOUSA-FELIX et al., 2017).

A estrutura do DPSIR adotada neste trabalho é descrita em Gari et al. (2015) e Sousa-Felix et al. (2017), levando em consideração: Forçantes (naturais e antrópicas), Pressões (alteração da paisagem e 
poluição), Estado (naturais e sociais), Impactos (diretos e indiretos) e Respostas. As técnicas, índices e dados utilizados no DPSIR seguiram os procedimentos metodológicos usados por Sousa-Felix et al. (2017).

\section{RESULTADOS E DISCUSSÃO}

\section{Análise da Capacidade de Carga Recreacional e DPSIR}

A Tabela 1 apresenta as áreas totais e utilizáveis para as quatro praias em estudo, indicadores e a Capacidade de Carga Recreacional - CCR. A praia com maior superfície é Atalaia, seguida de Ajuruteua, Maçarico e Princesa. Contudo, houve uma redução significativa da área usada nas praias de Ajuruteua e Atalaia. A distribuição espacial dos usuários destas praias é modulada principalmente pela amplitude das marés, acessibilidade e ocorrência de eventos culturais.

Tabela 1: Área total e utilizável, indicadores e Capacidade de Carga Recreacional - CCR para as praias de Ajuruteua, Atalaia, Maçarico e Princesa.

\begin{tabular}{|c|c|c|c|c|}
\hline \multirow{2}{*}{ Indicadores } & \multicolumn{4}{|c|}{ Praias } \\
\hline & Ajuruteua & Atalaia & Maçarico & Princesa \\
\hline Área total $\left(\mathrm{m}^{2}\right)$ & 1.140 .000 & 1.740 .000 & 724.550 & 399.000 \\
\hline Área usada $\left(\mathrm{m}^{2}\right)$ & 240.000 & 900.000 & 150.500 & 180.500 \\
\hline CCF (pessoa) & 24.000 & 90.000 & 15.050 & 15.041 \\
\hline Qualidade da água & 0,3 & 0,1 & 0,2 & 0,8 \\
\hline Qualidade ambiental & 0,85 & 0,85 & 0,85 & 0,95 \\
\hline Qualidade ecológica & 0,73 & 0,7 & 0,73 & 0,87 \\
\hline Qualidade de serviços & 0,8 & 0,9 & 0,71 & 0,71 \\
\hline CCR (pessoa) & 3.574 & 4.819 & 1.326 & 7.061 \\
\hline
\end{tabular}

Os parâmetros utilizados para avaliar a qualidade da água (QA) demonstraram valores insatisfatórios para as praias de Ajuruteua, Maçarico e Atalaia, onde está última apresentou a pior qualidade da água $(0,1)$. Esse indicador está diretamente relacionado ao descarte de esgoto doméstico lançado diretamente na praia. Ademais, para o indicador de qualidade ambiental (Qamb) todas as praias tiveram valores satisfatórios onde a Praia da Princesa registrou o maior valor $(0,95)$.

A qualidade ecológica (QE) da praia da Princesa foi considerada excelente devida a conservação de dunas e manguezais e poucas áreas com erosão. Entretanto, as praias Ajuruteua, Atalaia e Maçarico foram consideradas regulares, destacando a praia do Atalaia e Ajuruteua, que possuem uma quantidade expressiva de ocupação humana irregular em áreas de dunas, restingas e manguezais.

Ao analisar a qualidade dos serviços (QS), a praia da Princesa e Maçarico obtiveram a pontuação mais baixa $(0,71)$ devido à pouca oferta de serviços. A praia do Atalaia apresentou melhores qualidades de serviços, contudo, tais serviços necessitam de melhor planejamento em sua execução.

A CCR é apresentada demonstrando uma significativa diminuição na capacidade de todas as praias. Apesar de Ajuruteua e Atalaia possuírem uma extensa faixa utilizável, a CCR sugere a diminuição drástica no número de pessoas quando aplicado os indicadores de qualidade, principalmente qualidade da água e qualidade ecológica. A praia da Princesa, apesar de não possuir significativas qualidades de serviços, é considerada como mais adequada a receber um maior número de pessoas.

Com base na estrutura do DPSIR e nas características locais de cada área de estudo, foram 
identificadas as forçantes naturais e antrópicas. As forçantes naturais em evidência nas quatro praias são atreladas as dinâmicas atmosféricas e oceanográficas. Com isso, as pressões naturais observadas são alta energia hidrodinâmica, elevada descarga fluvial em estuários e marés equinociais de sizígia 2 vezes ao ano.

Além disso, a dinâmica de precipitação sazonal é marcada por um período chuvoso (primeiro semestre) influenciado principalmente pela Zona de Convergência Intertropical e pelas Linhas de Instabilidade Costeira e, por um período menos chuvoso e seco (segundo semestre) caracterizado pela atuação de ventos intensos de leste (SOUZA et al., 2019; SOUZA et al., 2020). A faixa de marés, altura das ondas, dinâmica de precipitação e presença de vazão dos rios foram observados para avaliar o desconforto dos turistas e da comunidade e os possíveis riscos para os serviços e infraestrutura oferecidos.

A ausência de planejamento e estratégias sistemáticas de manejo para o uso da praia é a principal forçante antrópica observada. O uso e ocupação inadequada das praias estudadas com superlotação e falta de organização de atividades recreativas são as forçantes mais significativas. A erosão e a qualidade da água são afetadas pelas forçantes naturais e antrópicas juntas pois a combinação de fatores ecológicos como alta energia hidrodinâmica, ventos intensos, vazão de rios e manguezais e, fatores sociais como ocupação desordenada e falta de saneamento básico alteram suas características.

Diante das forçantes demonstradas, as pressões naturais das quatro praias são: erosão (mudanças no perfil da praia), extenso período com elevada precipitação (aproximadamente seis meses) que limitam o desenvolvimento de atividades turistas e alta turbidez da água (devida à elevada descarga fluvial) gerando desconforto para banhistas. Para as pressões antrópicas a falta de planejamento para o desenvolvimento socioeconômico das praias resulta em: uso e ocupação desordenado do solo, ausência de saneamento básico (descarte de resíduos sólidos e esgoto doméstico) e ausência de gerenciamento costeiro e infraestrutura adequada (serviços, recreação e segurança). A Figura 2 demonstra as pressões observadas nas praias do Atalaia e Ajuruteua.

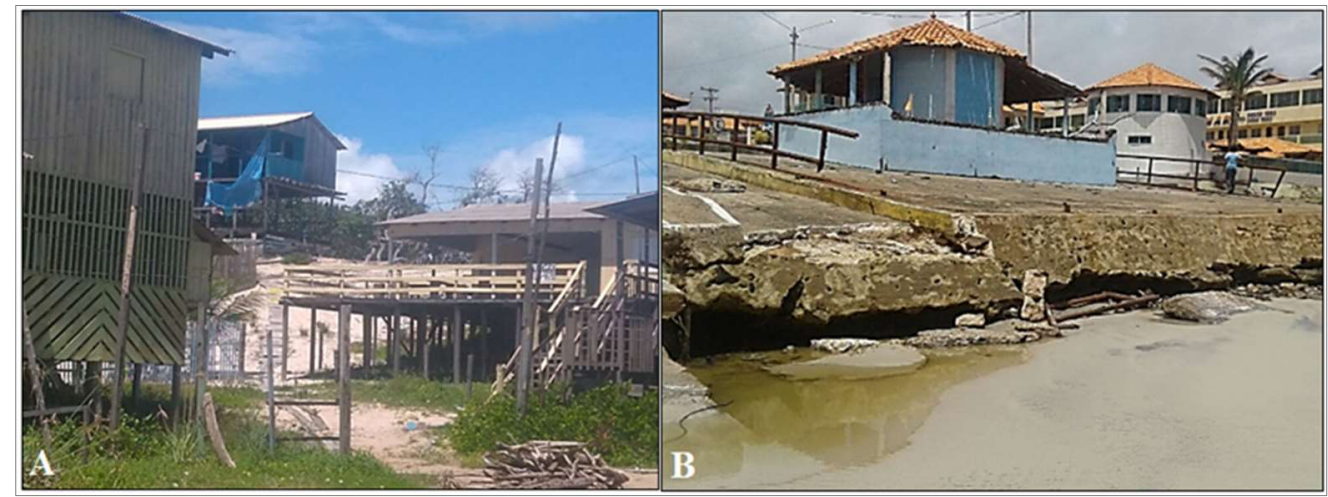

Figura 2: Ocupações humana em áreas de dunas na praia de Ajuruteua (A); Condições inadequadas de infraestrutura, segurança e acessibilidade na praia do Atalaia (B).

O Estado do ambiente é resultante do equilíbrio entre as forçantes naturais e antrópicas que moldam as características da paisagem. Nesse sentido, o Estado atual das quatro praias analisadas, principalmente Ajuruteua e Atalaia, é bastante similar. Durante o pico de visitação das praias nos finais de semana de julho (veraneio amazônico), a infraestrutura e os serviços locais são totalmente inadequados para atender às 
necessidades dos turistas. A falta de saneamento básico desencadeia um acúmulo significativo de resíduos sólidos nas praias e um excesso na descarga de esgoto (Figura 3). A entrada e uso de veículos na praia do Atalaia configura insegurança aos banhistas e gera poluição sonora a partir de aparelhos de som nos veículos.

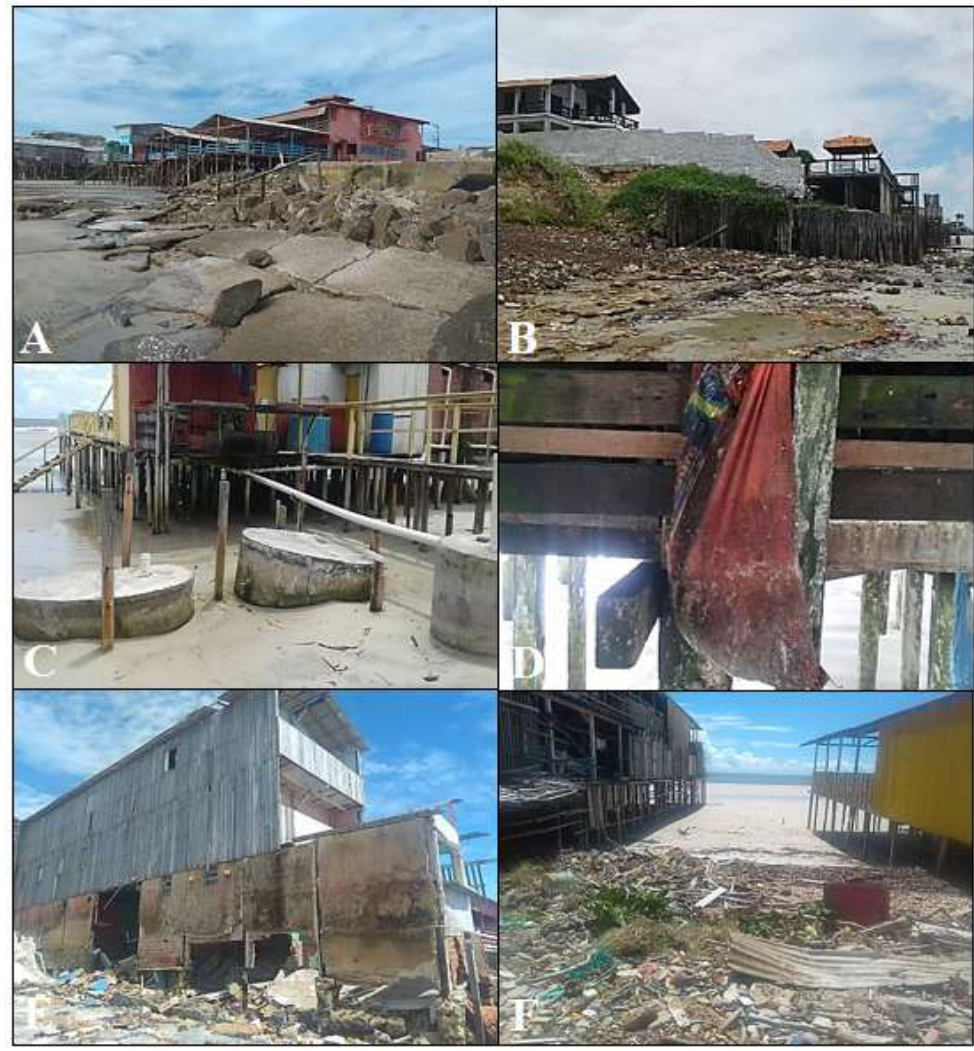

Figura 3: Sucateamento de infraestrutura (A) e descarte de resíduos sólidos (F) na praia de Ajuruteua; Erosão (B), sistema de esgoto doméstico danificado (C), contenção irregular de sólidos e gordura de esgoto (D) e estrutura abandonada oferecendo ricos de segurança (E) na praia do Atalaia.

A praia da Princesa apresenta o melhor Estado, devido está localizada em uma Unidade de Conservação (área de proteção ambiental) e possui políticas específicas de gestão. Contudo, durante o veraneio amazônico e feriados a superlotação de turistas e a pouca infraestrutura local desencadeia um expressivo problema de poluição da praia por resíduos sólidos. Além disso, a falta de zoneamento para atividades recreativas, a ausência de sinais de alerta e o número inadequado de salva-vidas contribuem para a presença de perigos e o risco de acidentes em todas as praias estudadas.

Os Impactos são as consequências de mudanças nos Estados naturais e antrópicos do ambiente. Os principais impactos registrados são apresentados na Tabela 2 para cada praia estudada.

Tabela 2: Principais Impactos observados nas praias de Ajuruteua, Atalaia, Maçarico e Princesa.

\begin{tabular}{lllll}
\hline \multirow{2}{*}{ Impactos } & Praias & & & \\
\cline { 2 - 5 } & Ajuruteua & Atalaia & Maçarico & Princesa \\
\hline Erosão da paisagem natural & $\mathrm{X}$ & $\mathrm{X}$ & $\mathrm{X}$ & $\mathrm{X}$ \\
Alteração da qualidade da água & $\mathrm{X}$ & $\mathrm{X}$ & $\mathrm{X}$ & $\mathrm{X}$ \\
Poluição acústica e visual & $\mathrm{X}$ & $\mathrm{X}$ & & $\mathrm{X}$ \\
Poluição por resíduo sólidos & $\mathrm{X}$ & $\mathrm{X}$ & $\mathrm{X}$ & $\mathrm{X}$ \\
Sucateamento da infraestrutura & $\mathrm{X}$ & $\mathrm{X}$ & & \\
Alagamentos de casas e estabelecimento & $\mathrm{X}$ & $\mathrm{X}$ & & $\mathrm{X}$ \\
Acidentes & $\mathrm{X}$ & $\mathrm{X}$ & $\mathrm{X}$ & \\
\hline
\end{tabular}

Diante do que foi apresentado nos resultados, observa-se que as pressões antrópicas possuem um 
peso significativo no estado em que as praias se encontram e nos impactos avaliados. Contudo, como respostas a este cenário, observa-se que os problemas estão relacionados a falta de planejamento do desenvolvimento local e ocupação das praias afetando diretamente ambientes como dunas e manguezais. Além disso, a falta de investimento em infraestrutura gera poluição através do descarte de esgoto doméstico e resíduos sólidos.

\section{Implicações no Desenvolvimento do Litoral Paraense}

A Capacidade de Carga Recreacional é considerada uma importante ferramenta no gerenciamento de praias, conservação da paisagem naturais e serviços (GARI et al., 2015). As quatro praias estudadas apresentaram significativa diminuição em suas capacidades. Essa diminuição também foi observada por Sousa et al. (2017) ao analisar praias estuarinas na costa amazônica. A qualidade da água geralmente é o indicador que mais afeta a CCR das praias bem como sua balneabilidade (MARTINS et al., 2017; MEDEIROS et al., 2016).

Embora a CCR revele o número ótimo de visitantes que o ambiente pode acolher, os índices de qualidade indicam especificamente onde as ações de gestão devem ser priorizadas, considerando a infraestrutura, serviços e as condições naturais que podem estar sendo insuficientes para satisfazer as necessidades da população local e dos turistas, afetando diretamente o desenvolvimento econômico (ZACARIAS, 2013).

A estrutura do DPSIR demonstrou o Estado em que as praias estudadas se apresentam e os principais impactos observados. Esse cenário não é diferente do observado por Santos et al. (2020) que destacaram a construção irregular de barracas e o descarte de resíduos sólidos como os principais problemas observados na praia do Lembe, no município de Marapanim - PA. Jambeck et al. (2015) destacam o descarte de resíduos sólidos e esgoto doméstico como o principal problema socioambiental em praias durante épocas de alta temporada.

Os problemas socioambientais, apresentados na Tabela 2, revelam que as praias do Atalaia e Ajuruteua são as mais impactadas pela falta de planejamento. Almeida et al. (2018) explicam que os municípios de Salinópolis e Bragança onde essas praias estão localizadas, foram as pioneiras no desenvolvimento do turismo do litoral paraense. Obras de expansão rodoviária e urbanização das praias foram alvo de investimentos para atrair o turismo nessas regiões. Contudo, fica evidente que esse desenvolvimento não foi planejado seguindo as políticas de gerenciamento costeiro e de sustentabilidade.

Coelho-Pessoa et al. (2019) ressaltam que o planejamento adequado da gestão costeira e as políticas públicas para o desenvolvimento do turismo são essenciais para evitar os impactos causados por pressões naturais e antrópicas, como apresentado através do DPSIR, sugerem que pode garantir o estado mais adequado do ambiente. A gestão pública local é considerada fundamental na aplicação das ações de conservação ambiental e organização das atividades recreativas. É necessário que essas ações sejam planejadas e aplicadas juntamente ao setor privado e moradores locais.

O PNGC é uma ferramenta política fundamental no planejamento e desenvolvimento da costa. Além 
do Plano Nacional, os municípios costeiros devem elaborar e executar seus Planos municipais observando normas, critérios e padrões relativos ao controle e à manutenção da qualidade do meio ambiente. A PNGC considera os seguintes aspectos a serem contemplados: urbanização; ocupação e uso do solo, do subsolo e das águas; parcelamento e remembramento do solo; sistema viário e de transporte; sistema de produção, transmissão e distribuição de energia; habitação e saneamento básico; turismo, recreação e lazer; patrimônio natural, histórico, étnico, cultural e paisagístico.

A urbanização irregular das praias desencadeia um problema urbano típico que é a falta de saneamento básico. Andrades et al. (2020) discutem que a presença de lixo nas praias pode afetar suas características naturais e reduzir seu valor econômico. Cavalcante et al. (2020) explicam que resíduos sólidos são descartados em praias e estuários e levados diretamente para o mar, contribuindo para um problema mundial de alto impacto ecológico.

A aplicação de Planos de Gestão Integrada de Resíduos Sólidos (PGIRS) e Planos Municipais de Saneamento Básico (PMSB) pode contribuir politicamente nas ações de desenvolvimento local dos municípios costeiros e colaborar na conservação da paisagem e dos recursos naturais. É importante ressalta que a população local deve participar no planejamento e aplicação das políticas públicas de desenvolvimento socioeconômico e ambiental (ALMEIDA et al., 2019; CRISTIANO et al., 2020).

Através da análise dos resultados, pode-se sugerir ações que os gestores locais podem realizar para reduzir os impactos e melhorar o estado das quatro praias estudadas: (I) A aplicação de um sistema de gerenciamento de resíduos sólidos (limpeza, coleta, reciclagem e destinação final) em todas as praias, que suporte a alta demanda durante o período de veraneio; (II) A suspensão imediata de descarte de esgoto doméstico nas praias, estuários, dunas e manguezais e a implantação de um sistema de coleta e tratamento de esgoto que atenda a realidade de cada praia; (III) o zoneamento e controle de construção de residências e edifícios próximo dunas ou manguezais; (VI) implantação de um sistema de monitoramento da qualidade da água e balneabilidade em pontos utilizados para banho e atividades recreativas; (V) campanhas de educação ambiental voltados principalmente a sensibilização do descarte de resíduos sólidos nas praias para turistas e população local.

\section{CONCLUSOES}

Os métodos de CCR e DPSIR foram eficazes para demonstrar os problemas socioambientais nas praias do litoral paraense. Essas metodologias são empregadas em diversos estudos (GARI et al., 2015; ZACARIAS, 2013; SOUSA et al., 2017; PEREIRA et al., 2014; SOUSA-FELIX et al., 2017; MONTEIRO et al., 2016; MEDEIROS et al., 2016) e contribuem significativamente no planejamento e desenvolvimento socioeconômico local.

O Estado em que as praias se encontram sugere que as políticas públicas adotadas pelo governo do Estado e municípios não estão sendo eficazes ou não estão sendo aplicadas corretamente. Cabe aos órgãos de fiscalização ambiental investigar possíveis crimes ambientais decorrentes das pressões antrópicas observadas para coibir essas pressões e minimizar os impactos ambientais no litoral.

Em 2019 o Governo Federal, através do Ministério do Meio Ambiente (MMA), criou a Agenda 
Nacional de Qualidade Ambiental Urbana, definida com o objetivo de melhorar os indicadores da boa qualidade ambiental em áreas urbanas. Essa Agenda Nacional orienta para políticas públicas urgentes, mais efetivas e eficientes, que integrem condutas nos diferentes níveis de tomadas de decisão. Após a consolidação de diversos diagnósticos, seis linhas de ação foram estabelecidas e uma dessas linhas é 'O combate ao lixo no mar'.

Essa linha de prioridade visa atuar diretamente no combate de resíduos sólidos que são descartados ou chegam nas áreas costeiras. Como ferramenta política foi lançado o Plano Nacional de Combate ao Lixo no Mar ${ }^{1}$. De acordo com o MMA, aproximadamente 400 toneladas de resíduos foram coletadas em 200 ações de limpeza envolvendo mais de 40 mil participantes, e cobrindo mais de 100 municípios nos 17 estados costeiros.

O combate ao lixo no mar é mais uma ferramenta técnica e política que os gestores dos municípios costeiros do litoral paraense, em especial Salinópolis, Bragança e Marapanim, podem utilizar para desenvolver ações eficazes de desenvolvimento socioeconômico, proteção ambiental e investimento turístico. $\mathrm{O}$ apoio do Governo Federal nesse sentido, é fundamental para obtenção de recursos financeiros e assessoria técnica. Além disso, os recentes estudos de Almeida et al. $(2018 ; 2019 ; 2020)$ trazem informações científicas significativamente relevantes que podem ser usadas por gestores municipais e comunidades locais para melhor planejamento de políticas públicas e tomadas de decisões.

\section{REFERÊNCIAS}

ALMEIDA, A. F.; JARDIM, M. A. G.. Análise dos indicadores de desenvolvimento socioeconômico, urbano e turístico decorrentes dos investimentos das políticas públicas nas praias do Crispim, Atalaia e Ajuruteua, Pará, Brasil. Journal of Integrated Coastal Zone Management, v.19, n.4, p.191207, 2020. DOI: http://dx.doi.org/10.5894/rgci-n114

ALMEIDA, A. F.; JARDIM, M. A. G.. Atuação da comunidade local nas políticas públicas de desenvolvimento socioeconômico e ambiental. Revista Brasileira de Geografia Física, v.12, n.5, p.1823-1834, 2019. DOI: https://doi.org/10.26848/rbgf.v12.5.p1823-1834

ALMEIDA, A. F.; JARDIM, M. A. G.. Mudanças socioeconômicas e ambientais resultantes das políticas públicas de desenvolvimento socioeconômico no litoral do Nordeste do Pará, Brasil. Desenvolvimento e Meio Ambiente, v.49, 2018. DOI: http://dx.doi.org/10.5380/dma.v49i0.55128

ANDRADES, R.; PEGADO, T.; GODOY, B. S.; REIS FILHO, J. A.; NUNES, J. L.; GRILLO, A. C.; KUHNEN, V. V.. Anthropogenic litter on Brazilian beaches: Baseline, trends and recommendations for future approaches. Marine Pollution Bulletin, v.151, p.110842, 2020. DOI: https://doi.org/10.1016/j.marpolbul.2019.110842

BRASIL. Lei Federal n.7661 de $\mathbf{1 6}$ de maio de 1988. Institui o Plano Nacional de Gerenciamento Costeiro e dá outras providências. Brasília: DOU, 1988.
CAVALCANTE, R. M.; PINHEIRO, L. S.; TEIXEIRA, C. E.; PAIVA, B. P.; FERNANDES, G. M.; BRANDÃO, D. B.; SCHETTINI, C. A. Marine debris on a tropical coastline: Abundance, predominant sources and fate in a region with multiple activities (Fortaleza, Ceará, northeastern Brazil). Waste Management, v.108, p.13-20, 2020. DOI: https://doi.org/10.1016/i.wasman.2020.04.026

COELHO-PESSOA, R. M.; JIMÉNEZ QUINTANA, J. A.; COSTA, R. M.; PEREIRA, L. C. C.. Federal conservation units in the Brazilian amazon coastal zone: an adequate approach to control recreational activities? Ocean and Coastal Management, v.178, p.104856-1-104856-10, 2019. DOI: https://doi.org/10.1016/i.ocecoaman.2019.104856

CRISTIANO, S. C.; ROCKETT, G. C.; PORTZ, L. C.; SOUZA FILHO, J. R.. Beach landscape management as a sustainable tourism resource in Fernando de Noronha Island (Brazil). Marine Pollution Bulletin, v.150, p.110621, 2020. DOI: https://doi.org/10.1016/j.marpolbul.2019.110621

GARI, S. R.; NEWTON, A.; ICELY, J. D.. A review of the application and evolution of the DPSIR framework with an emphasis on coastal social-ecological systems. Ocean \& Coastal Management, v.103, p.63-77, 2015. DOI: https://doi.org/10.1016/j.ocecoaman.2014.11.013

GRILLI, N.; XAVIER, L.; JACOBI, P.; TURRA, A.

Sustentabilidade das regiões costeiras e oceânicas: necessidade de um novo relacionamento entre ciência e

${ }^{1}$ https://www.mma.gov.br/agenda-ambiental-urbana/lixo-no-mar.html 
gestão. Revista USP, v.113, p.45-58, 2017. DOI: https://doi.org/10.11606/issn.2316-9036.v0i113p45-58

JAMBECK, J. R.; GEYER, R.; WILCOX, C.; SIEGLER, T. R.; PERRYMAN, M.; ANDRADY, A.; LAW, K. L.. Plastic waste inputs from land into the ocean. Science, v.347, n.6223, p.768-771, 2015. DOI:

https://doi.org/10.1126/science.1260352

MARTINELLI FILHO, J. E.; MONTEIRO, R. C. P.. Widespread microplastics distribution at an Amazon macrotidal sandy beach. Marine Pollution Bulletin, v.145, p.219-223, 2019. DOI: https://doi.org/10.1016/j.marpolbul.2019.05.049

MARTINS, L. M.; MEDEIROS, L.; ROSAS, R.; REIS, A. L.. Análise dos parâmetros de balneabilidade: um estudo de caso sobre as praias dos municípios de João Pessoa e Cabedelo/PB. Revista InterScientia, v.5, n.1, p.116-128, 2017.

MEDEIROS, E. C. S.; MAIA, L. P.; ARAÚJO, R. C. P.. Capacidade de carga de uma praia sob o impacto do processo de erosão costeira (praia do Icaraí): Subsídios para o gerenciamento costeiro do estado do Ceará, Brasil. Revista de Gestão Costeira Integrada, v.16, n.2, p.185-193, 2016. DOI: https://dx.doi.org/10.5894/rgci592

MONTEIRO, M. C.; JIMÉNEZ, J. A.; PEREIRA, L. C. C.. Natural and human controls of water quality of an Amazon estuary (Caeté-PA, Brazil). Ocean \& Coastal Management, v.124, p.42-52, 2016. DOI: https://doi.org/10.1016/j.ocecoaman.2016.01.014

OLIVEIRA, F. P.; NAHUM, V. J. I.; JOANA, D.; VIEIRA, N. C.. Percepção dos extrativistas estuarino-costeiros sobre as práticas e os impactos socioambientais nos manguezais do Nordeste paraense, costa amazônica brasileira. Educamazônia-Educação, Sociedade e Meio Ambiente, v.18, n.2, p.73-104, 2017.

PEREIRA, L. C. C.; VILA-CONCEJO, A.; COSTA, R. M.; SHORT, A. D.. Managing physical and anthropogenic hazards on macrotidal Amazon beaches. Ocean \& Coastal Management, v.96, p.149-162, 2014. DOI: https://doi.org/10.1016/j.ocecoaman.2014.05.008

PEREIRA, L. C. C.; SOUSA-FELIX, R. C.; COSTA, R. M.; QUINTANA, J. A. J.. Challenges of the recreational use of Amazon beaches. Ocean and Coastal Management, v.165, p.52-62, 2018. DOI:

https://doi.org/10.1016/i.ocecoaman.2018.08.012
PINTO, R.; JONGE, V. N.; NETO, J. M.; DOMINGOS, T.; MARQUES, J. C.; PATRÍCIO, J.. Towards a DPSIR driven integration of ecological value, water uses and ecosystem services for estuarine systems. Ocean \& Coastal Management, v.72, p.64-79, 2013. DOI: https://doi.org/10.1016/j.ocecoaman.2011.06.016

SANTOS, M. C.; CANTO, O.; BASTOS, R. Z.; FENZL, N.; TUPIASSU, L.; SOMBRA, D.. Conflito e gestão ambiental na zona costeira amazônica: O caso da vila do Camará, reserva extrativista (RESEX) marinha mestre lucindo, MarapanimPará-Amazônia-Brasil. Brazilian Journal of Development, v.6, n.3, p.15607-15617, 2020. DOI: https://doi.org/10.34117/bjdv6n3-439

SOUSA, R. C.; PEREIRA, L. C. C.; COSTA, R. M.; JIMÉNEZ, J. A.. Management of estuarine beaches on the Amazon coast though the application of recreational carrying capacity indices. Tourism Management, v.59, p.216-225, 2017. DOI: https://doi.org/10.1016/j.tourman.2016.07.006

SOUSA-FELIX, R. C.; PEREIRA, L. C. C.; TRINDADE, W. N.; SOUZA, I. P.; COSTA, R. M.; JIMENEZ, J. A.. Application of the DPSIR framework to the evaluation of the recreational and environmental conditions on estuarine beaches of the Amazon coast. Ocean \& Coastal Management, v.149, p.96106, 2017. DOI: https://doi.org/10.1016/i.ocecoaman.2017.09.011

SOUZA, H. E. N.; VITORINO, M. I.; BISPO, C. J. C.; MARINHO, E. R.; DIAS, F. G.; SARDINHA, A. S.; COUTINHO, E. C.. Variabilidade e potencial da fonte eólica para geração de energia elétrica na costa amazônica. Revista IberoAmericana de Ciências Ambientais, v.11, n.1, p.400-410, 2020. DOI: http://doi.org/10.6008/CBPC21796858.2020.001.0036

SOUZA, H. E. N.; VITORINO, M. I.; VASCONCELOS, S. S.; MARINHO, E. R.; BISPO, C. J. C.. Influência de Sistemas Precipitantes sobre a Produção de Serapilheira em Manguezal da Costa Amazônica. Revista Brasileira de Ciências Ambientais, v 54, p.105-118, 2019. DOI: http://dx.doi.org/10.5327/Z2176-947820190571

ZACARIAS, D. A.. Avaliação da capacidade de carga turística para gestão de praias em Moçambique: o caso da Praia do Tofo. Revista de Gestão Costeira Integrada, v.13, n.2, p.205$214,2013$.

A CBPC - Companhia Brasileira de Produção Científica (CNPJ: 11.221.422/0001-03) detém os direitos materiais desta publicação. Os direitos referem-se à publicação do trabalho em qualquer parte do mundo, incluindo os direitos às renovações, expansões e disseminações da contribuição, bem como outros direitos subsidiários. Todos os trabalhos publicados eletronicamente poderão posteriormente ser publicados em coletâneas impressas sob coordenação da Sustenere Publishing, da Companhia Brasileira de Produção Científica e seus parceiros autorizados. Os (as) autores (as) preservam os direitos autorais, mas não têm permissão para a publicação da contribuição em outro meio, impresso ou digital, em português ou em tradução. 